\title{
INTRODUCCIÓN: ART DÉCO COMO PATRIMONIO E IDENTIDAD
}

Paul M aenz (Art D éco: 1920-1940) escribía en 1974, refiriéndose al Art Déco que «El término aparece por vez primera en 1966 con ocasión de la muestra retrospectiva «LesAnnées 25» celebrada en el Musée des Arts Décoratifs de París». Sin embargo, desde entonces las producciones y los al cances de la estética Déco no han dejado de valorarse en el conjunto de la producción de un siglo XX contradictorio y convulso. Así podría entenderse el Déco como una tendencia general, una sucesión de cristales irisados que reflejaban de forma distinta y con diferentes colores una misma necesidad de moder nidad.

El Art Déco en arquitectura vino a reflejar las mismas contradicciones al pretender una búsqueda de la modernidad a toda costa, sin alterar las esencias de una arquitectura entendida como ornamento y elegancia. Pero al mismo tiempo también se constituye en el último estilo o tendencia que aspiraba a una visión optimista de la vida, refinada y a la vez decadente, una opción más del periodo de entreguerras. Las superficies planas, con detalles geométricos, quebrados, formando zig-zags interminables 0 atrevidas curvas aerodinámicas no son otra cosa que una forma de presentar de forma popular los avances del cubismo o de algunas corrientes de vanguardia, limando los atrevimientos de éstas y transformando su impulso en formas estéticas codificadas.

Muchas ciudades buscaban precisamente esa imagen de modernidad en sus arquitecturas Art Déco. Ciudades europeas, pero curiosamente y sobre todo urbes de América, África y Asia, que se tomaban una cierta revancha sobre el viejo continente en los desenfrenos ornamentales y en los recubrimientos fulgurantes del estilo. Y por esta razón, resulta totalmente oportuno analizar el caso concreto de algunas de estas urbes, que en una abultada lista nos permite recorrer ciudades como París, Milán, Tesalónica, Heliópolis, Argel, Casablanca o M elilla.

El Centro Asociado a la U niversidad Nacional de Educación a Distancia de M elilla se viene comprometiendo en esta línea de promoción del conocimiento cientí- 
fico de una forma activa. Desde 2002 participó en un proyecto internacional Euromed Heritage II, denominado Patrimoines Partagés, lo que permitió establecer una red de investigadores centrada fundamentalmente en los modelos arquitectónicos del siglo XX. Fruto de ese proyecto ya surgió una publicación Arquitecturas y ciudades hispánicas de los siglos XIX y XX en torno al M editerráneo occidental (2005), que abordaba la importancia del fenómeno arquitectónico y urbano en este periodo.

Algunos de los muchos frutos que esta intensa relación han reportado, pueden verse también reflejados en el I Congreso Ciudad y Patrimonio que volcó sus esfuerzos en abordar un interesante capítulo de la arquitectura del siglo XX: el Art Déco. En este congreso participaron algunos profesores que ya habían colaborado en el proyecto Patrimoines Partagés, junto a otros especial istas que podían iluminar interesantes aspectos relativos a este capítulo de la historia del arte del siglo XX.

Con ello, la UNED intenta proyectarse en los trabajos de vanguardia que en el ámbito científico internacional se desarrollan al respecto. Por esta razón, era obligado poder ofrecer un congreso en español y en francés con traducción simultánea, y trasladar este carácter internacional a la publicación que aquí se presenta, donde se ha optado por ofrecer los textos en los dos idiomas, con el fin de poder multiplicar su influencia y sus posibles lectores.

En este monográfico deALDABA se recogen arquitecturasArt Déco de una buena serie de países que pueden nuclearse en torno al M editerráneo, aunque no todas sean ciudades propiamente mediterráneas. De este modo, España, Francia, Italia, Grecia, Egipto, Argelia y M arruecos han recibido la atención de los profesores e investigadores que firman sus correspondientes capítulos, demostrando cómo el Art Déco es un fenómeno de trascendencia internacional y que por esta misma razón, debe ser abordado desde un prisma que supere el propiamente localista.

Por otra parte, este monográfico libro que se integra dentro de la revista Aldaba, de gran tradición investigadora, pretende recoger en lo fundamental la idea del citado congreso, aunque los capítulos han sido elaborados a posteriori y han recogido nuevos elementos por lo que no son unas actas propiamente dichas. El congreso permitió reunir a un grupo de expertos internacionales sobre Art Déco y fomentar el debate y la reflexión.

La arquitectura de M elilla se abrió paso en el panorama nacional e internacional a partir de varios congresos celebrados en la ciudad desde 1985, que permitieron la aportación de algunos de los más prestigiosos especialistas sobre la materia. A hora pretendemos diversificar con este trabajo lo que ya se inició en su momento, enriqueciendo con un nuevo capítulo aquella diversidad de tendencias que ya se apuntaba 
hace más de veinte años. M elilla ciudad Art N ouveau, pero también ciudad Art D éco, es una de las ideas que pretendemos plantear en estas páginas, pero sobre todo que este estilo une a algunas de las grandes capitales mediterráneas que comparten su patrimonio.

En esta obra contamos con la participación de exper tos internacionales en Art Déco. Francisco J avier Pérez Rojas (Catedrático de H istoria del A rte de la U niversidad deValencia, España) ofrece un interesante e intenso recorrido por la exposición de París de 1925 que nos permite apreciar sus principales características y los diversos pabellones que la conformaron. Por su parte Ezio Godoli (Profesor de Historia de la Arquitectura y de la Ciudad, U niversidad de Florencia, Italia) anal iza en su capítulo la figura del arquitecto M arcello Piacentini y su influencia en el Art D éco y en la arquitectura de los cines en Italia, realizando una aproximación tanto formal como tipológica en este tipo de edificios. Abderrahim Kassou (Investigador de la Fundación Casamémoire, Casablanca, Marruecos), aborda un interesante panorama de la arquitectura Déco de Casablanca, centrándose en diver sos aspectos de sus artesanías y la influencia que éstas tuvieron en la definición del estilo. Panorama parecido es el apuntado por Boussad Aiche (Profesor del Departamento de Arquitectura de la universidad M ouloud M ammeri de Tizi-O uzou, Argelia) sobre la ciudad de Argel.

MercedesVolait (Directora de investigación en el Centre National de la Recherche Scientifique, Francia) aborda la ciudad de Heliópolis, en las afueras de EI Cairo, y cómo los modelosArt Déco prenden en su arquitectura. Vassilis Colonas (Profesor de $\mathrm{H}$ istoria de la Arquitectura de la U niversidad de Thesal ia, Grecia), nos ofrece un intenso panorama de la arquitectura D éco en Grecia, centrándose en diferentes arquitecturas. Romeo Carabelli (profesor de la U niversidad deTours, Francia) abordó por su parte una novedosa aproximación al Art D éco centrada en cómo el mercado de arte y las diferentes exposiciones cel ebradas sobre este estilo han marcado su puesta en val or.

Finalmente Antonio Bravo N ieto (Profesor del Centro A sociado a la UNED en Melilla y del Departamento de Historia del Arte de la U niversidad de Málaga, España) aborda el desarrollo del Art Déco en M elilla desde sus inicios hasta su declive en sus variantes zigzagueantes y aerodinámica, abordando en otro capítulo cómo la destrucción del Cine M onumental fue un punto de partida para la conservación del patrimonio arquitectónico melillense.

Reseñar, por último, que con este ejemplar de «ALDABA» cumple sus primeros 25 años. En estos años se han publicado artículos de todas las disciplinas del ámbito universitario. $\mathrm{H}$ an colaborado, prácticamente, profesores e investigadores de toda España y de nuestro entorno hispánico. Gracias a todos ellos. 
Mi más sincera felicitación a todos los profesores-tutores de la U NED-M eliIla y a los investigadores melillenses que con su colaboración desinteresada han hecho posible la existencia de «ALDABA», especialmente a dos extraordinarios colaboradores como Antonio Bravo Nieto yVicente M oga Romero.

Pero he de manifestar aquí que sin la iniciativay el apoyo de D. Ramón Gavilán A ragón, nuestro director (nuestro siempre extraordinario director amigo) no hubiese sido posible esta publicación. Muchas gracias.

José MegíasAznar

Secretario del Centro Asociado a la UNED en Melilla 